\title{
Global challenges of cancer imaging: perspective from different parts of the world: Asia
}

\author{
Pek-Lan Khong \\ From International Cancer Imaging Society (ICIS) 14th Annual Teaching Course \\ Heidelberg, Germany. 9-11 October 2014
}

Asia accounts for about $60 \%$ of the world's population and half the global burden of cancer [1]. Due to the diverse economic development across the Asian continent, countries have highly variable health services development and healthcare infrastructure. Thus, there is disparity in access to services, especially resource intensive cancer management. All countries in Asia, except Japan are defined by the UN as 'less developed regions' and this reflects the limited resources in general. This presentation aims to describe the demographic characteristics of cancer in Asia, and highlight the challenges and main advancements of cancer imaging across this region.

Lung cancer is the most common cancer in men (35.2/100,000 persons) and breast cancer the most common cancer in women (29.1/100,000 women) in Asia.

The incidence rate of breast cancer in Asia is about 1/3 compared to North America (NA) and Western Europe (WE), although it is on a steady rise. However, the five year prevalence rate is manifold lower indicating that in proportion, there are fewer cancer survivors in Asia. With the exceptions of Japan, South Korea and Taiwan, resources in most countries are inadequate for population-based organised screening mammography programmes. However, it is less clear if organised screening would be a cost-effective programme in Asia, due to the lower incidence rate as well as reduced sensitivity of mammography in Asian women with higher density breast tissue [2], and there is evidence that supplemental ultrasound screening increases the sensitivity for cancer detection in women with dense breasts [3].

Notably, in South East Asia (SEA) and East Asia (EA) compared to the rest of the world, the incidences of liver cancer, oesophageal cancer, stomach cancer and nasopharyngeal cancer are relatively high, although on the decline. Liver cancer is the second and third most common cancer in men in SEA and EA respectively, and fifth most common cancer in women. More than $70 \%$ of the new cases of liver cancer are from Asia, of which $50 \%$ are from China. Recent studies have advanced the use of gadolinium ethoxybenzyl dimeglumine (Gd-EOB-DTPA) enhanced MRI for its superior sensitivity for the detection of hepatocellular carcinoma, especially small tumors [4], and 11C-acetate PET imaging for detection of well-differentiated tumors [5]. Oesophageal cancer is the fifth most common cancer in EA men. Asia accounts to about $75 \%$ of new cases, specifically the 'asian oesophageal cancer belt' that extends from Turkey to Mongolia and Western/Northern China. The majority of these are squamous cell carcinoma in histology. Studies have found 18F-Fluorodeoxyglucose (FDG) PET to be useful in disease staging (particularly upstaging), and predictive of outcome of neo-adjuvant chemotherapy and disease survival [6]. Nasopharyngeal carcinoma is the sixth and fourteenth most common cancer in men across SEA and EA respectively. $80 \%$ of new cases are from this region, and are focussed around Southern China, Taiwan and SEA. Current research has evaluated the roles of diffusion MRI for tissue characterisation [7] and 18F-FDG PET for prognostication [8].

In recent years the cancer burden in Asia and its developing countries has surged, and is forecasted to continue to rise. Resources for the provision and development of diagnostic imaging which plays an essential role in early detection and management of cancer must be supported and strengthened across the region. 


\section{References}

1. GLOBOCAN 2012 [http://globocan.iarc.fr].

2. Yoo KB, Kwon JA, Cho E, et al: Is mammography for breast cancer screening cost-effective in both western and Asian countries?: results of a systematic review. Asian Pac J Cancer Prev 2013, 14:4141-4149.

3. Chae EY, Kim HH, Cha JH, et al: Evaluation of screening whole breast sonography as a supplemental tool in conjunction with mammography in women with dense breasts. J Ultrasound Med 2013, 32:1573-78.

4. Liu X, Zou L, Liu F, et al: Gadoxetic acid disodium-enhanced magnetic resonance imaging for the detection of hepatocellular carcinoma: a meta-analysis. PLOS one 2013, 8:1-9.

5. Ho CL, Yu SC, Yeung DW: $11 \mathrm{C}$-acetate PET imaging in hepatocellular carcinoma and other liver masses. J Nucl Med 2003, 44:213-21.

6. Yanagawa $M$, Tatsumi $M$, Miyata $H$, et al: Evaluation of response to neoadjuvant chemotherapy for esophageal cancer: PET response criteria in solid tumors versus response evaluation criteria in solid tumors. J Nucl Med 2012, 53:872-80.

7. Lai V, Li X, Lee VHF, et al: Intravoxel incoherent motion MR imaging: Comparison of diffusion and perfusion characteristics between nasopharyngeal carcinoma and post-chemoradiation fibrosis. Eur Radiology 2013, 23:2793-2801.

8. Chang KP, Tsang NM, Liao CT, et al: Prognostic significance of 18F-FDG PET parameters and plasma Epstein-Barr virus DNA load in patients with nasopharyngeal carcinoma. J Nucl Med 2012, 53:21-8.

doi:10.1186/1470-7330-14-S1-O3

Cite this article as: Khong: Global challenges of cancer imaging:

perspective from different parts of the world: Asia. Cancer Imaging 2014 14(Suppl 1):O3.

\section{Submit your next manuscript to BioMed Central} and take full advantage of:

- Convenient online submission

- Thorough peer review

- No space constraints or color figure charges

- Immediate publication on acceptance

- Inclusion in PubMed, CAS, Scopus and Google Scholar

- Research which is freely available for redistribution 